\title{
Implementation 4 - DoF Arm Robot Object Sorting Controlled Based On Color Using Inverse Kinemathics Algorithm
}

\author{
Kunto Aji W ${ }^{1}$, Haryanto ${ }^{2}$, Edi Nuralim ${ }^{3}$, Riza Alfita ${ }^{4}$, Rosida Vivin Nahari ${ }^{5}$, Mirza Pramudia ${ }^{6}$, Achmad Fiqhi \\ Ibadillah $^{7}$ \\ Faculty of Engineering \\ University Of Trunojoyo Madura \\ Bangkalan, Indonesia \\ ${ }^{1}$ kunto.utm@gmail.com, ${ }^{2}$ Haryanto_UTM@yahoo.com, ${ }^{3}$ edinuralim25@gmail.com, ${ }^{4}$ riza_alvita@trunojoyo.ac.id, \\ ${ }^{5}$ rosida_vn@yahoo.com, ${ }^{6}$ mirza_ub@yahoo.com, ${ }^{7}$ fiqhi.achmad@gmail.com
}

\begin{abstract}
Arm manipulator is one type of robot that is widely applied in the industrial world. Robots of this type are commonly used to help people in the hard work, dangerous or repetitive work. The needs of industrial machine in Indonesia have been increasing based on industrial development that has been increasing too in Indonesia. Some kind of industry producing a different kind of package for one product. So it needs a machine that can clarify the product based on the packaging. The purpose of this study was to design a mechanical configuration model consisting of $4 \mathrm{DOF}$ arm robots and conveyors, which are used as objects separating objects based on color. A 4 DOF arm manipulator prototype designed as sorting object by color in this research. The arm manipulator's prototype using inverse kinematics motion in determining the position of the sorted object transfer. Photodiode detector is used in order to distinguish the object based on its colors. The output of this research is to produce a 4 DOF arm manipulator prototype that can move and sort object by its color. From the experimental results of tests performed with the initial position of the robot is able to move the object from the initial coordinates to the coordinates that have been determined according to the color of the object point, the time it took an average of $9.71 \mathrm{~s}$ with an average error of $24.5 \%$. In testing the sensor TCS3200 almost perfect but still a bit error due to the influence of outside light. To test the robot was very good overall level of success achieved has been $86.66 \%$. Based on the results of testing that has been done by the robot arm 4 DOF inverse kinematic methods and trajectory planning is very effective in making the process move stuff. With the implementation of the research, it is expected that an alternative development model for industrial control system technology will be achieved by integrating arm robots and conveyor movements so that this can improve system efficiency.
\end{abstract}

Keywords-arm robot; inverse kinematics; object sorting; Introduction

\section{INTRODUCTION}

In the era of globalization, market competition becomes tight. The main reason for using robots in the world industry is for a fee issued. Besides that, robots can also work faster, accurate, durable and more flexible. Robots are created very diverse, such as legged robots, wheeled robots and robots that move in all directions there are even robots that resemble humans even though only certain parts, such as heads, feet or arms. The arm manipulator robot that has been widely applied in industrial fields, such as welding robots, robot handling, punching robots, robotic machine tools, etc. [1]. Robot arm is not only used in industry, but also used in the field of research and health. An example is the robot arm inside industry is a welding robot from Fanuc Industry and painting robots manufactured by Kawasaki. One of the forms of robot arm that is often used is the arm anthropomorphic robot model. This robotic arm has flexibility in operational mode in 3-dimensional space, so it is suitable for application in most industrial robots [2][3].

In general, the structure of the robot arm consists of arms and wrists. The arm part is composed of a series of links, with one link configuration with the other link connected with the joint component. With the joint connecting the two links, the joint will form a degree of freedom. While at the end of the robot arm is equipped with end-effectors with a gripper model that is used to perform a particular purpose [4]. In another study there was the development of an arm robot control system, in the form of a dual arm robot controller [10].

Many studies explain the use of arm robots in industry. Some studies use manual control as a movement instruction for robot arm [5]. While other studies, color codes are used for the selection process. In another study, the robot arm used was in the form of a 3 DOF configuration (Degree of freedom) [6]. In this study the robot arm was developed using the 4 DOF (Degree of freedom) model. In the sorting process, 4 different object colors are used: red, green, blue and yellow.

In the next process, automatic control based on inverse kinematic method is used to control the movement of arm robots in order to move objects to a place that match the object's color. the purpose of this study was to design a mechanical configuration model consisting of $4 \mathrm{DOF}$ arm robots and conveyors, which are used as objects separating objects based on color. 
In this case a mechanical model scheme is designed that configures two main components, consisting of arm robots that move with kinematic inverse algorithms and conveyors as object detection drive systems. A color sensor with type TCS3200 is used as an object color detector. The purpose of the mechanical configuration in this study is as a new form in the development of a control model in industrial robotics technology that combines robotic arm control and conveyor movement control. The combination of synchronous control between4 DOF arm robots and conveyors in the object sorting process is expected to improve the efficiency and performance of the system

\section{DESIGN Of The CONTROL SySTEM}

The Robot DO manipulator 4 DOF designed in this study is a prototype scale. This robot is designed to be able to sort items by color and move according to the place. For determine the position of the end-effectors movement of the robot is used geometry inverse kinematics motion method [7].

\section{A. Design Of Arm Robot For Color-Based Object Sorting}

The mechanical structure of the robot arm consists of several parts and the most important part is the servo motor. Servo motors used in the robot arm are hitech with type hs 422, which produces a maximum torque of $3 \mathrm{~kg}$. The total number of servo motors used for robotic mechanics is 5 units, consisting of 4 hitech motor types hs 422 and 1 servo type pro mg tower 90s. This servo motor is arranged with a combination of 3 servo motors used as joints and one servo motor is used as a robot base. As for the servo motor with towerpro type, it is used as a gripper, while the aim is to reduce the load on the robot arm. For more details, see Fig. 1.

From Fig. 1 the robot arm mechanical system is shown which consists of the following parts:

- Base is the basic part of the robot arm and the place of the servo motor base.

- The base of the robot arm, this part is the base board of the robot arm made of wooden boards.

- Servo base motor, this motor is used as a robot driving the bottom so that it can move in 3-dimensional direction.

- Link 1, is the first part of the arm with a horizontal static position.

- Servo link 2 motor, is a motor that functions to move arm part 2.

- $\quad$ Link 2, is arm part 2.

- Servo motor link 3 , is a servo motor that functions to move arm part 3.

- Link 3, is a robot arm part 3.

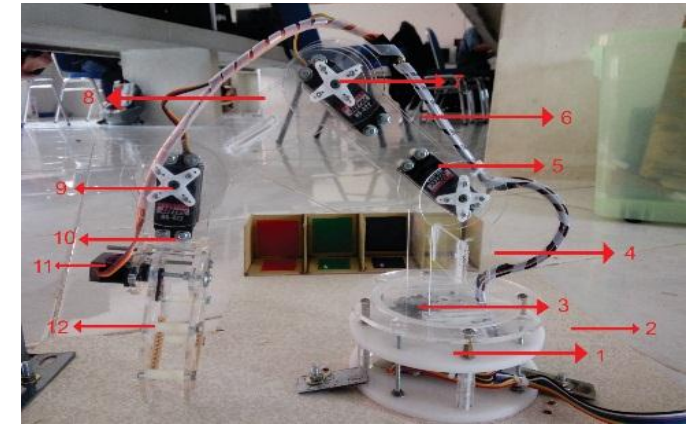

Fig. 1. Mechanical Structure Of 4-DoF Arm Robot

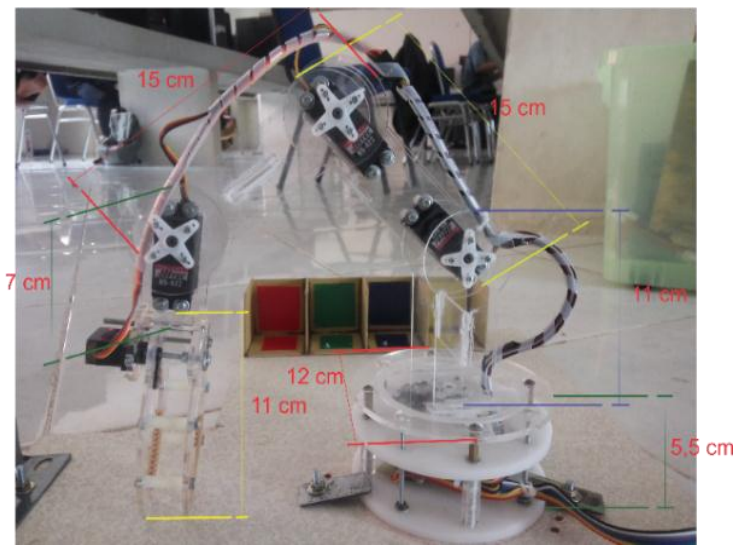

Fig. 2. Dimension Configuration Of $4-$ DoF Arm Robot

- Servo motor link 4 , is a servo motor that functions to move the robot arm part 4.

- Link 4, is the robot arm part 4

- Gripper servo motor, this motor is used to move the gripper in the open or close process.

- Gripper (clamp), this section is useful as a clamp object when the object will be moved to another place

The size of the robot mechanics is adjusted to the torque characteristics of the servo motor. So that the mechanical design is designed not to exceed $3 \mathrm{~kg}$. A detailed measure of the mechanical structure of the robot arm is shown in Fig. 2 below.

The basic material of this robot arm uses acrylic with a thickness of $2 \mathrm{~mm}$, the purpose of using $2 \mathrm{~mm}$ acrylic is to keep the robot light but still strong. For the design process each part of the robot uses Corel Draw X5 Software.

\section{B. Hardware Connection Diagram}

In this research, a 4-dof arm robot has been designed to move objects and place objects automatically in a place with a color code on an object. Fig. 3 shows the block process diagram of the system based on the design of the robot arm sorting object; 


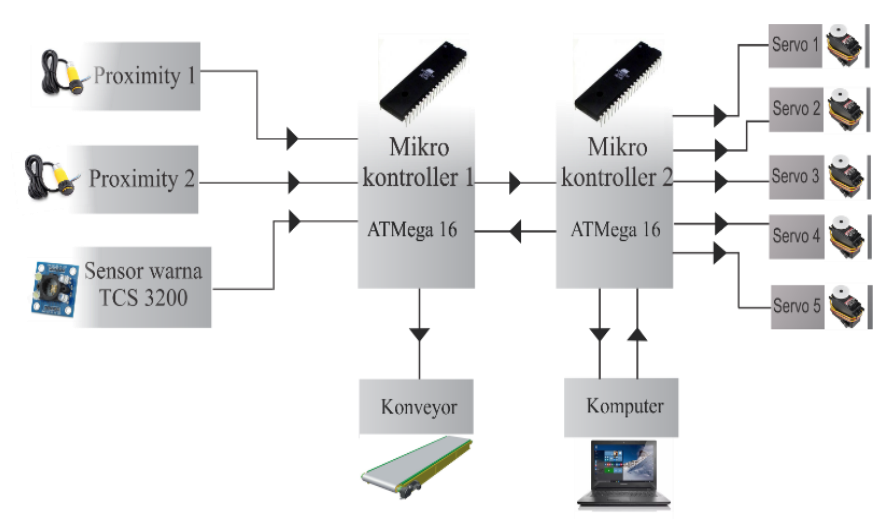

Fig. 3. System Diagram Block Of 4 DoF Arm Robot

\section{Hardware Implementation}

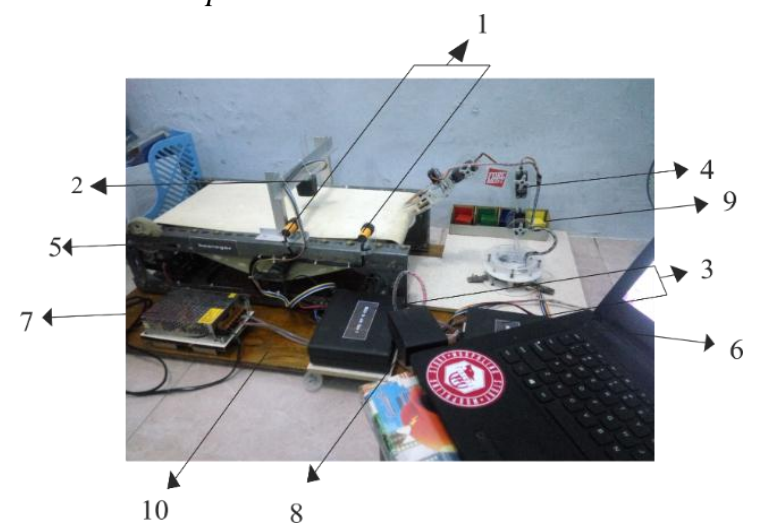

Fig. 4. Implementation of 4 DoF Arm Robot

Designing a robot arm 4 DOF object sorting is done using a servo motor actuator as the main component. The sensor used for object color detection is TCS3200. While the controller used is the ATmega16 microcontroller which functions to read sensor data, process algorithms, communicate with computers through interfaces and adjust the servo controller position changes. Robot 4 DOF prototype arm designed on this research can be seen as Fig. 4.

The whole system is shown in Fig. 4 which consists of the following sections:

1. Proximity 1 and Proximity 2, this component is used as a sensor for detecting objects. Proximity 1 for first position and proximity 2 for position 2 .

2. The TCS 3200 sensor, this section functions as the initialization of the object.

3. The first microcontroller and the second microcontroller, there are two microcontrollers in this sorting system, the first microcontroller is used as a control of the entire system on the conveyor and the second microcontroller is used as a robot arm control.

4. 4 DOF arm robot, is a robot that is used as a moving object from the conveyor to the object's place.

5. Conveyors, these conveyors are used as a place to initialize objects with a moving state
6. Laptop is parts that are used as a place to monitor the GUI from the work system.

7. DC Power Supply, this section is used as the overall power supply system.

8. USB TTL, this part is used as communication between laptop and hardware.

9. Place of sorted object is the place of objects placed that has been splitted by its color.

\section{Software Implementation}

The interface application on the computer is designed to perform various tests and control the 4 DOF arm robot. Experiments that can be done on robot arm by using interfaces namely serial communication testing, servo motor testing, and robot motion kinematics testing.

In addition, the application interface that is designed is also useful to control the robot arm, which is as the provider of the command to start, stop, and provide data transfer locations. Fig. 5 shows the application display interface designed in this research.

\section{INVERSE KINEMATICS ALGORITHM}

By looking at the geometry model in Fig. 6, the kinematic inverse for the arm robot can be determined in order to define the value of $\theta_{1}, \theta_{2}, \theta_{3}$ and $\theta_{4}$. In determining the value of each $\theta$ the value of the $\mathrm{x}, \mathrm{y}, \mathrm{z}$ coordinates and the length of the link (L1, L2) must be known. The equation used to solve this problem is [8]:

$$
\theta_{1}=\left(\operatorname{atan}^{2}(y, x)\right)
$$

The input used in equation (1) is the value of the $\mathrm{x}$ and $\mathrm{y}$ coordinates, which are the target coordinates, then the value $\theta_{1}$ will be obtained. After $\theta 1$ is obtained then determine the value of $\theta_{2}, \theta_{3}$ and $\theta_{4}$. In defining the third value $\theta$ it is necessary to get the values of $a$ and $b$ first, and to be able to determine the values of $\mathrm{a}$ and $\mathrm{b}$, it is done by finding the value of the arm length $(\mathrm{L})$

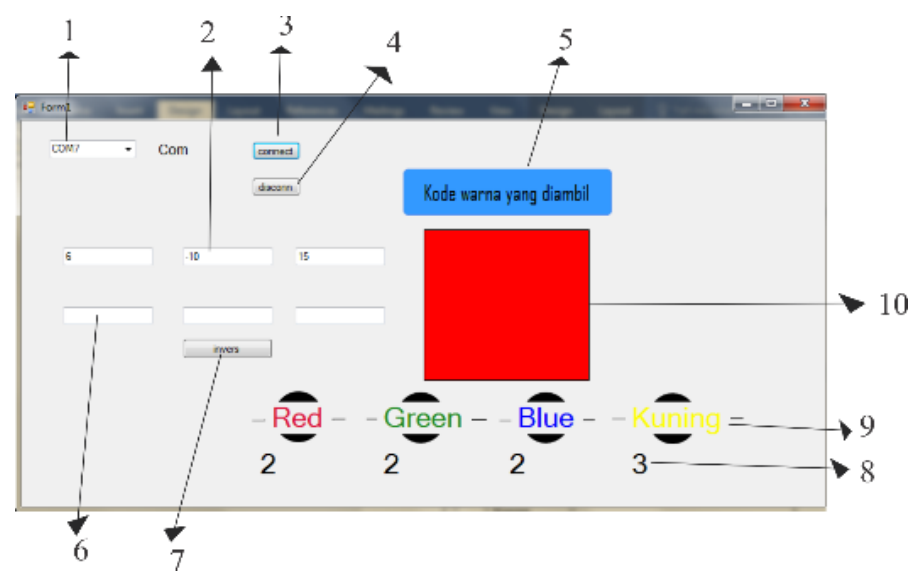

Fig. 5. Implementation of Interface Aplication Of 4 DoF Arm Robot

The formula for finding the length of the Arm, L, a and b can be obtained using equations 2 to 5

$$
\text { ArmLength }=\sqrt{((x * x)-(y * y))}
$$




$$
\begin{gathered}
L=\sqrt{((\text { ArmLength } \times \text { ArmLength })-(z * z))} \\
a=\frac{\left((L * L)-\left(l_{1} * l_{1}\right)-\left(l_{2} * l_{2}\right)\right)}{2 * l_{1}}
\end{gathered}
$$

After the variable values of $a$ and $b$ are obtained, the next step is to enter the value into the formula $\theta_{3}$, using the following equation 6 :

$$
\theta_{3}=\operatorname{atan}^{2}(b, a) \times \frac{180}{3,14}
$$

After finding the value $\theta_{3}$ then look for the value $\theta_{2}$ by using the following equation 7 :

$$
\theta_{2}=\left(\operatorname{atan}^{2}\left(\mathrm{~b},\left(\mathrm{l}_{1}+\mathrm{a}\right)\right)\right)+\left(\mathrm{a} \tan ^{2}\left(\mathrm{z}, \mathrm{arm} \_ \text {length }\right)\right)
$$

After the values of $\theta_{3}$ and $\theta_{2}$ are obtained, then determine the value of $\theta_{4}$ by using equation 8 :

$$
\theta_{4}=\left(\theta_{3}+\theta_{2}\right) \times(-1)
$$

The following is a description of each variable from the equations used:

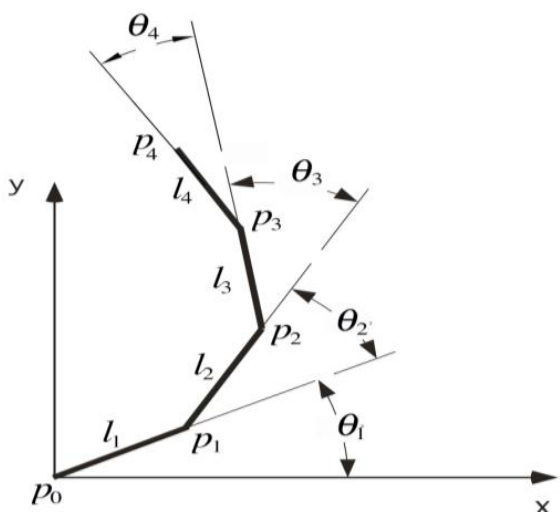

Fig. 6. Geometry Model Of 4 DoF Arm Robot

TABLE I. D - H PARAMETER OF 4 DOF ARM RoBOT

\begin{tabular}{|c|c|c|c|c|}
\hline Join & $\begin{array}{c}\text { Link } \\
\text { Lenght } \\
(\boldsymbol{\alpha} \mathbf{)}\end{array}$ & $\begin{array}{c}\text { Link } \\
\text { offset } \\
(\mathbf{d} 1)\end{array}$ & $\begin{array}{c}\text { Joint } \\
\text { angle } \\
(\boldsymbol{\theta i})\end{array}$ & $\begin{array}{c}\text { Twist angle } \\
(\boldsymbol{\alpha i})\end{array}$ \\
\hline 1 & 0 & $15 \mathrm{~cm}$ & $\theta 1$ & $90^{0}$ \\
\hline 2 & $10 \mathrm{~cm}$ & 0 & $\theta 2$ & 0 \\
\hline 3 & $10 \mathrm{~cm}$ & 0 & $\theta 3$ & 0 \\
\hline 4 & $6 \mathrm{~cm}$ & 0 & $\theta 4$ & 0 \\
\hline
\end{tabular}

- $\theta 1=$ Servo angle 1

- $\quad \theta 2=$ Servo angle 2

- $\theta 3=$ Servo angle 3

- $\theta 4=$ Servo angle 4
- $\mathrm{L}=$ overall arm length

- $y=y$-axis coordinate

- $\mathrm{x}=\mathrm{x}$-axis coordinate

- $\mathrm{z}=\mathrm{z}$ axis coordinate

- $\quad$ Arm $=$ arm length per joint

To solve the equation in kinematic inverse algorithm, the D$\mathrm{H}$ parameter configuration is used as table 1 below:

\section{Simulation AND ANALYSis Of The System}

The experiment was carried out to determine the conditions and results of the prototype robot arm designed. Testing was also conducted to determine the ability of the arm robot to sort and move objects according to their color.

\section{A. Color Sensor Testing}

Color sensor testing is done to determine the output voltage of each color. Table 2 is the result of dividing the filter reference range for each color category. The colors used are red, green, yellow and blue.

\section{B. Kinematics Inverse Testing}

Testing of inverse kinematics is done to test the precision of the robot's arm to move to a certain position and to determine the change in angle of each joint. In this inverse kinematics test contains testing of $\mathrm{X}$ axis variations, $\mathrm{Y}$ axis variations, and variations of $\mathrm{Z}$ axis[9].

Kinematic inverse testing is done by setting the initial coordinates and target coordinates of the arm robot. Then the last position of the robot will be calculated as the final position. The difference in value between the target position and the initial position is calculated as a position error. Kinematic inverse test results are shown in table 3 . Based on data shown in table 3 , the error value can be calculated on each axis. The average time taken for each test was $9.73 \mathrm{~s}$, for the target time of $10 \mathrm{~s}$, so that the average error time achieved was $24.5 \%$

\section{Object Sorting Test}

The sorting test is carried out to determine the capabilities of this robot arm as robots designed to sort items, so this test needs to be done to find out this ability.

In this test the whole process is complete, starting from placing objects in the specified position on the conveyor, until the objects are grouped according to their color. Illustration of the testing process shown in Fig. 7.

TABLE II. COLOR SENSOR TESTING RESUlt

\begin{tabular}{|l|l|l|}
\hline No & \multicolumn{1}{|c|}{ Object Color } & \multicolumn{1}{c|}{ Range Filter Reference $(\mathbf{H z})$} \\
\hline 1 & Blue & $2000>$ value $>1400$ \\
\hline 2 & Red & $3000>$ value $>2000$ \\
\hline 3 & Green & $4000>$ value $>3000$ \\
\hline 4 & Yellow & Value $>4000$ \\
\hline
\end{tabular}


TABLE III. INVERSE KINEMATHICS TESTING RESULT

\begin{tabular}{|l|l|l|l|l|}
\hline $\begin{array}{c}\text { Mot } \\
\text { ion }\end{array}$ & $\begin{array}{c}\text { Initial } \\
\text { coordinate }\end{array}$ & $\begin{array}{c}\text { Target } \\
\text { Coordinate }\end{array}$ & $\begin{array}{c}\text { Final } \\
\text { Coordinate }\end{array}$ & $\begin{array}{c}\text { Average } \\
\text { Time }\end{array}$ \\
\hline 1 & $3,0,30$ & $6,-10,15$ & $6,-12,15$ & 09,80 \\
\hline 2 & $3,0,30$ & $3,-10,15$ & $4,-11,15$ & 09,71 \\
\hline 3 & $3,0,30$ & $-2,-10,15$ & $-2,-11,15$ & 09,73 \\
\hline 4 & $3,0,30$ & $-5,-10,15$ & $-5,-10,15$ & 09,71 \\
\hline \multicolumn{4}{|c|}{ Average Time } & 9,73 \\
\hline
\end{tabular}

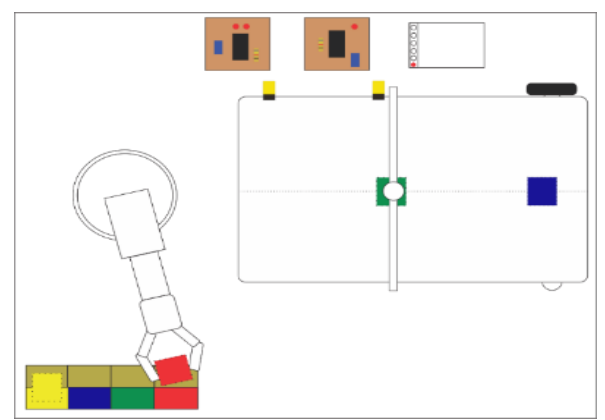

Fig. 7. Work Ilustration Of 4 DoF Arm Robot

From Fig. 7 it can be seen that the arm robot moves towards the coordinates based on kinematic inverse algorithm to do the sorting process determined according to the results of the color sensor data. The position of the sorting results is distinguished by the color of each object. Each color position is given a different initial label. for the red color label 1 is given, for green is labeled 2, while for blue is label 3 and for yellow is labeled 4 . In table 4 shows the results of testing the whole robot by detecting the object colors and the results of the sorting process.

From table 4 it can be seen that the position of the coordinate points reached is correct but still experiencing some error. The final coordinate point is determined from the initialization of the TCS3200 color sensor, so if the sensor is not right in the color initialization process, then the coordinated target will also produce an error in the sorting process.

TABLE IV. OBJECT SORTING RESUlT

\begin{tabular}{|c|c|c|c|c|c|c|c|c|c|}
\hline \multirow{2}{*}{$\begin{array}{c}\text { Sam- } \\
\text { ple }\end{array}$} & \multirow{2}{*}{$\begin{array}{c}\text { Color } \\
\text { Object }\end{array}$} & \multicolumn{3}{|c|}{$\begin{array}{c}\text { Initial } \\
\text { coordinat }\end{array}$} & \multicolumn{3}{|c|}{ Final Coordinat } & \multirow{2}{*}{ مُ } & \multirow{2}{*}{ Result } \\
\hline & & $x$ & $y$ & $z$ & $x$ & $y$ & $z$ & & \\
\hline 1 & Red & 3 & 0 & 30 & 6 & -10 & 15 & 1 & Success \\
\hline 2 & Green & 3 & 0 & 30 & 3 & -10 & 15 & 2 & Success \\
\hline 3 & Yellow & 3 & 0 & 30 & -5 & -10 & 15 & 4 & Success \\
\hline 4 & Blue & 3 & 0 & 30 & -2 & -10 & 15 & 3 & Success \\
\hline 5 & Red & 3 & 0 & 30 & 6 & -10 & 15 & 1 & Success \\
\hline 6 & Blue & 3 & 0 & 30 & -2 & -10 & 15 & 3 & Success \\
\hline 7 & Yellow & 3 & 0 & 30 & -5 & -10 & 15 & 4 & Success \\
\hline 8 & Green & 3 & 0 & 30 & 3 & -10 & 15 & 2 & Success \\
\hline 9 & Yellow & 3 & 0 & 30 & -5 & -10 & 15 & 4 & Success \\
\hline 10 & Red & 3 & 0 & 30 & 6 & -10 & 15 & 1 & Success \\
\hline 11 & Green & 3 & 0 & 30 & 3 & -10 & 15 & 2 & Success \\
\hline 12 & Blue & 3 & 0 & 30 & -2 & -10 & 15 & 3 & Failed \\
\hline 13 & Green & 3 & 0 & 30 & 3 & -10 & 15 & 2 & Failed \\
\hline 14 & Yellow & 3 & 0 & 30 & -5 & -10 & 15 & 4 & Success \\
\hline 15 & Blue & 3 & 0 & 30 & -2 & -10 & 15 & 3 & Success \\
\hline \multicolumn{9}{|c|}{ Success percentage } & $86,6 \%$ \\
\hline
\end{tabular}

Table 5 shows the results of the interface process between the data generated by the hardware and the GUI application. Tests are carried out to see the color equation of the object given with the reading displayed on the color code interface. In addition, it also sees the number of objects that have been moved by the robot arm. For the results of the gui test can be seen in table V.

TABLE V. GUI APLICATION TESTING RESUlt

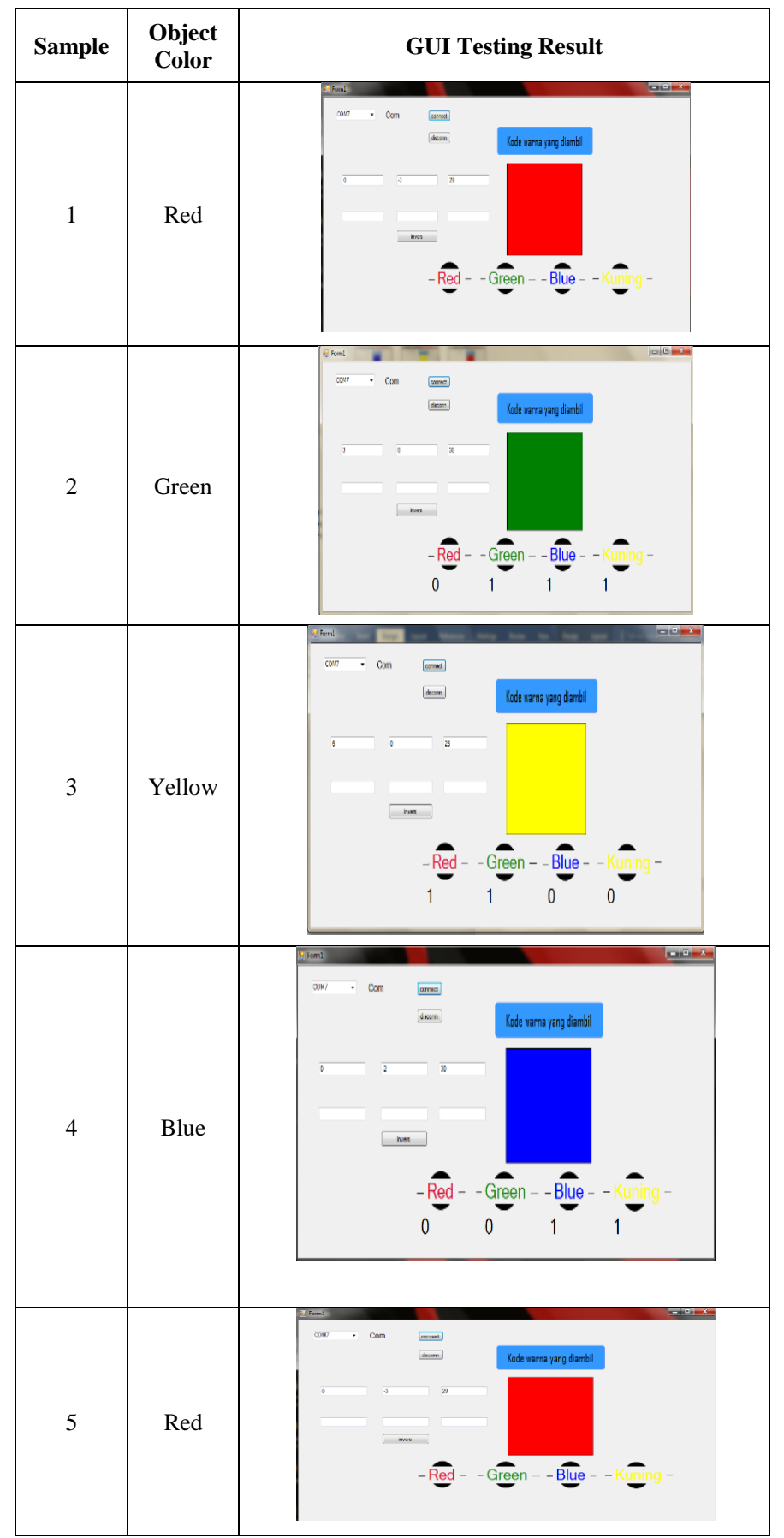




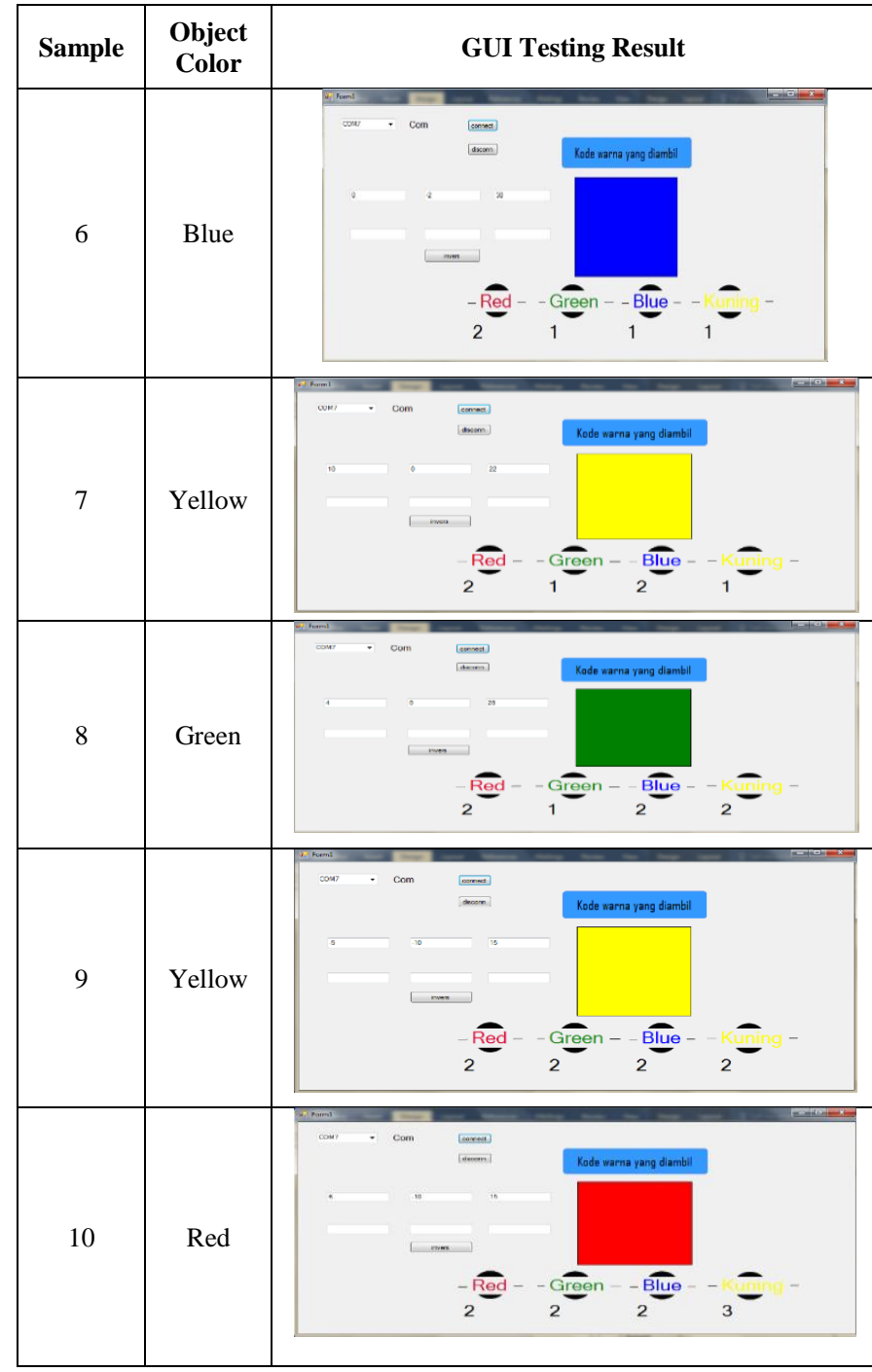

From table 5, it can be seen that the initialization and detection process of the TCS 3200 sensor is almost perfect but there is still an error for reading blue and green codes. This happened because the TCS 3200 sensor was very susceptible to external light. For the counter results from the process of moving objects to the place is still not perfect, this is because the initialization is not correct so the calculation of the counter will follow the color code taken

\section{CONCLUSION}

Based on the results of the design, implementation and testing of the system that has been made, the following conclusions can be drawn:

2D using the kinematic inverse method and trajectory planning robot arm can move according to the coordinates $\mathrm{x} y$ and $\mathrm{z}$ which are specified as the end points.

From the testing time of the robot's place in the process of placing objects to an average time required of $9,73 \mathrm{~s}$. In the overall test, it is known that the arm robot has a success rate of $86.6 \%$ in the process of sorting objects based on color.
The synchronous control system design model between robot arm and conveyor that has been implemented in this research, has shown significant results so that it can become an alternative control system that can be implemented in the applied industrial sector

As a model for further research development, the camera can be integrated as a color detector with the aim of increasing speed and accuracy in detecting object colors, so that it is expected to increase the efficiency and effectiveness of the system in achieving its function.

\section{ACKNOWLEDGMENT}

We would like to thank our colleagues in Faculty of Engineering University of Trunojoyo Madura

\section{REFERENCES}

[1] M. F. Faris, A. Triwiyatno, "Perancangan ARM Manipulator 4 DoF dengan menggunakan pengendalian cartesian space line trajectory planning (Designing ARM Manipulator $4 \mathrm{DoF}$ using cartesian space line trajectory planningcontrol)", Universitas Diponegoro, Semarang, 2012.

[2] E. Nuralim, K. A. Haryanto, Perancangan Sistem Sortir Robot Arm 4 DoF Dengan Metode Trajectory Planning dan Inverse Kinematik, Universitas Trunojoyo: Bangkalan, 2012.

[3] M. Januss, A. udal, V. Kukk, K. Umbleja, "Implementation of the Robot Arm in the Interactive Learning Enviroment", Int. Conf. on Signal and Electron. Syst. (ICSES), pp. 1 - 4, 2014.

[4] Y. Si, Q. Jia, G. Chen, H. Sun,"A Complete Solution To The Inverse Kinematics Problem For 4 Dof Manipulator Arm Robot", 2013 IEEE $8^{\text {th }}$ Conf. on Ind. Electron. And Appl. (ICIEA), pp. 1880 - 1884, 2013.

[5] J. Huang, X. Wang, D. Liu, Y. Cui, “A new Method For Solving Inverse Kinematics Of An Industrial Robot”, 2012 Int. Conf. On Comput. Sci. And Electron. Eng., p. 53 - 56, 2012.

[6] F. Rong, J. Hehua, "High Precision Inverse Kinematics Based On Discrete Workspace For Obstacle Avoidance", $20122^{\text {nd }}$ Int. Conf. On Future Comput. And Commun., pp. V1608 - V1613, 2012.

[7] G. S. Huang, C. K. Tung, H. C. Li, S. H. Hsiao,'Inverse Kinematics Analysis Trajectory Planning For A Robot Arm", Proc. of $20118^{\text {th }}$ Asian Control Conf. (ASCC), pp. 965 - 970, 2011.

[8] O. Hock, J. Sedo,'Inverse Kinematics Using Transposition Method For Robotic Arm", 2018 IEEE Conf., pp. 1 - 5, 2018.

[9] C. Xia, X. Yang, W. Gu, ”A Kinematics Equation And Trajectory Planning Of Flexible Arm Space Robot", 2012 Third Int. Conf. On Intell. Control And Inf. Proc., pp. 417-421, 2012.

[10] H. Yamamoto, H. Moribe, T. Yamada, “UNARM System to Decide Units Locations of Cell Type Assembly Machine with Dual Arm Robots", J. Robot., Netw. And Artif. Life, vol. 4, no. 1, pp 41-44, 2017. 